Methods: Subjects who completed the double-blind placebo-controlled (DBPC) part of JBT101-DM-001 with 12 weeks of active dosing and 4 weeks of safety follow-up were eligible to receive lenabasum $20 \mathrm{mg}$ BID in an open-label extension (OLE). Safety and efficacy evaluations were done at Week 4 after the start of OLE, then every 8 weeks thereafter.

Results: $20 / 22$ (91\%) eligible subjects enrolled in the OLE and 17/20 (85\%) were on baseline immunosuppressive drugs. There was a mean interval of 31 weeks (range 4-92 weeks) from the end of active DBPC dosing and the start of the OLE, during which time subjects remained on background medications prior to adding lenabasum in the OLE. At the time of OLE data cut-off, no subjects had discontinued, all 20 subjects in the OLE completed visits through Week 12 and 11 subjects completed visits through Week 28. During the 28 weeks of OLE dosing, adverse events (AEs, $n=30$ ) occurred in $14 / 20(70 \%)$ subjects. Only 1 subject had a moderate $A E$, all other AEs were mild. Four (20\%) subjects had AEs considered related to lenabasum. The only $A E$ that occurred in more than 1 subject was $D M$ flare $(n=2,10 \%)$. During the OLE, there was improvement from the beginning of the OLE dosing and from the study start in Cutaneous Dermatomyositis Activity and Severity Index (CDASI) Activity score and physician Likert assessments of global disease activity, skin disease activity and extramuscular disease activity. Similarly, there were improvements in multiple patient-reported outcomes, including patient $10 \mathrm{~cm}$ VAS scores of global disease activity, skin disease activity, itch and pain, as well as the Skin-dex-29 symptoms domain and PROMIS-29 physical function, fatigue, pain interference, and anxiety domains. Selected efficacy outcomes are shown in figure 1 as change from study start during two periods: 1) "off treatment" from the end of active DBPC dosing to the start of OLE, dotted line; and 2) OLE dosing, solid line.
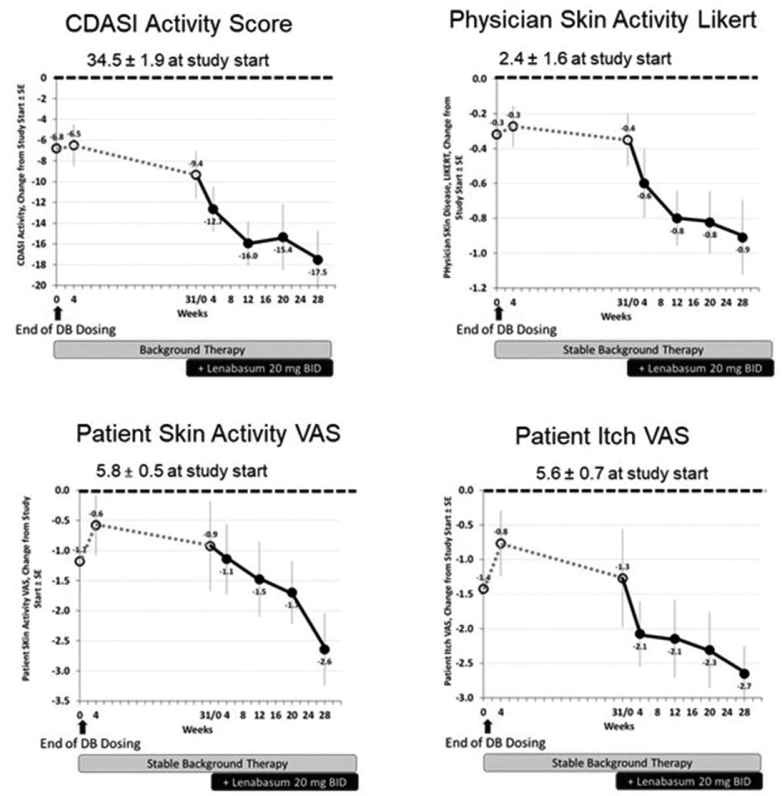

Abstract SAT0512 - Figure 1. Mean change from Baseline \pm SE in Selected Efficacy Outcomes

Conclusions: Lenabasum continues to have a favourable safety and tolerability profile in the OLE of the Phase 2 trial JBT101-DM-001 with no severe or serious AEs or study discontinuations related to lenabasum. The CDASI activity score and multiple other physician and patient-reported outcomes improved from study start and start of the OLE, although open-label nature of dosing with lenabasum is acknowledged. These data support further testing of lenabasum for the treatment of DM.

Disclosure of Interest: V. Werth Consultant for: Corbus Pharmaceuticals, Inc., B. Patel: None declared, J. Concha: None declared, J. Okawa: None declared, D. Pearson: None declared, E. Hejazi: None declared, R. Feng: None declared, C. Cornwall Employee of: Corbus Pharmaceuticals, Inc., N. Dgetluck Employee of: Corbus Pharmaceuticals, Inc., S. Constantine Employee of: Corbus Pharmaceuticals, Inc., A. Aggarwal Employee of: Corbus Pharmaceuticals, Inc., B. White Employee of: Corbus Pharmaceuticals, Inc. DOI: 10.1136/annrheumdis-2018-eular.5629

\section{SAT0513 \\ PROGRESSIVE SKIN FIBROSIS IS ASSOCIATED WITH A DECLINE IN LUNG FUNCTION AND POORER SURVIVAL IN PATIENTS WITH DIFFUSE CUTANEOUS SYSTEMIC SCLEROSIS: A EUROPEAN SCLERODERMA TRIALS AND RESEARCH (EUSTAR) ANALYSIS}

W. Wu ${ }^{1}$, S. Jordan ${ }^{1}$, N. Graf ${ }^{2}$, J. Pena ${ }^{3}$, J. Curram $^{4}$, Y. Allanore ${ }^{5}$, M. MatucciCerinic $^{6}$, J.E. Pope ${ }^{7}$, C. Denton ${ }^{8}$, D. Khanna ${ }^{9}$, O. Distler ${ }^{1}$ on behalf of EUSTAR coauthors. ${ }^{1}$ University Hospital Zurich, Zurich, Switzerland; ${ }^{2}$ Graf Biostatistics, Winterthur, Switzerland; ${ }^{3}$ Bayer US LLC, Parsippany, NJ, USA; ${ }^{4}$ Bayer PIC, Reading, UK; ${ }^{5}$ Cochin Hospital, Paris Descartes University, Paris, France; ${ }^{6}$ University of Florence, Florance, Italy; ${ }^{7}$ University of Western Ontario, St. Joseph's Health Care, London, ON, Canada; ${ }^{8}$ University College London, Royal Free Hospital, London, UK; ${ }^{9}$ University of Michigan, Ann Arbor, MI, USA

Background: Short disease duration and low baseline modified Rodnan skin score (mRSS) have been identified as independent predictors of progressive skin fibrosis in patients with diffuse cutaneous systemic sclerosis (dcSSc) using the EUSTAR database. ${ }^{1}$ However, whether worsening of skin fibrosis is an appropriate surrogate marker for new-onset or deterioration of visceral organ disease and overall survival in dcSSc has been questioned.

Objectives: To determine whether progressive skin fibrosis is associated with visceral organ progression and mortality in dcSSc patients during follow-up.

Methods: We performed a survival analysis of the EUSTAR database including patients with dcSSc, fulfilling the ${ }^{\text {ACR } 1980}$ criteria, with baseline mRSS $\geq 7$ in 2009 or later, valid mRSS at $12 \pm 3$ months after baseline and $>1$ available annual follow-up visit. Progressive skin fibrosis was defined as an increase in mRSS >5 units and $\geq 25 \%$ from baseline to $12 \pm 3$ months later. Disease outcome was defined as occurrence of one of the following new events during follow-up based on expert group consensus: relative decrease in forced vital capacity (FVC) $\geq 10 \%$; left ventricular ejection fraction (LVEF) $<45 \%$ or relative decrease in LVEF $>10 \%$ for patients with baseline LVEF <45\%; pulmonary hypertension globally judged on echocardiography by the treating physician; renal crisis; allcause death. The association between skin progression and disease outcomes over follow-up was evaluated by Kaplan-Meier analysis, log-rank test and multivariate Cox regression. Multiple imputation was used to handle missing values. Results: Among 1021 eligible dcSSc patients, 78 (7.6\%) had progressive skin fibrosis within 1 year (defined as progressors). The median follow-up period was 3.4 years. Survival analyses indicated that skin progressors had a significantly higher probability of FVC decline $>10 \%(53.6 \%$ vs $34.4 \% ; p<0.001)$ and all-cause death (15.4\% vs $7.3 \% ; p=0.003$ ) than non-progressors (figure 1). These significant associations between skin progression and FVC decline and all-cause death were also observed in the subgroup of patients with either baseline mRSS $\leq 22 / 51$ or disease duration $\leq 15$ months. Multivariate Cox regression confirmed that skin progression was independently associated with FVC decline $\geq 10 \%$ (HR 1.79, $95 \% \mathrm{Cl} 1.20$ to 2.65 ) and all-cause death (HR2.58, 95\% Cl 1.31 to 5.09 ).

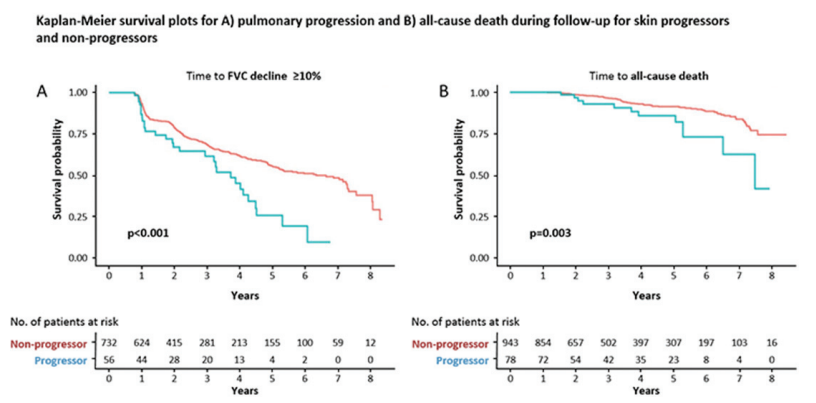

Abstract SAT0513 - Figure 1. Kaplan-Meier survival plots for A) pulmonary progression and $B$ ) all-cause death during follow-up for skin progressors and non-progressors

Conclusions: In patients with dcSSc, progressive skin fibrosis within 1 year is associated with a decline in lung function and worse survival over follow-up. This evidence-based finding is helpful for cohort enrichment in clinical trials for both skin and lung fibrosis, and for risk stratification in clinical practice.

\section{REFERENCE:}

[1] Maurer B, Graf N, Michel BA, et al. Prediction of worsening of skin fibrosis in patients with diffuse cutaneous systemic sclerosis using the EUSTAR database. Ann Rheum Dis 2015;74(6):1124-31.

Acknowledgements: The authors thank Gill Hill for editing the abstract. Disclosure of Interest: W. Wu: None declared, S. Jordan: None declared, N. Graf: None declared, J. Pena Employee of: Bayer HealthCare Pharaceuticals Inc, J. Curram Shareholder of: Bayer AG, Employee of: Bayer Plc, Y. Allanore Grant/ 
research support from: Actelion Pharmaceuticals US, Bayer AG, Bristol-Myers Squibb, Inventiva, Medac, Pfizer Inc, Roche Pharmaceuticals, Genentech and Biogen IDEC Inc. Sanofi-Aventis Pharmaceutical, Servier, Consultant for: Actelion Pharmaceuticals US, Bayer AG, Bristol-Myers Squibb, Inventiva, Medac, Pfizer Inc, Roche Pharmaceuticals, Genentech and Biogen IDEC Inc., SanofiAventis Pharmaceutical, M. Matucci-Cerinic Grant/research support from: Pfizer, Bristol-Myers Squibb, Actelion, UCB Pharma, Consultant for: Actelion, Bayer, ChemomAb, Genentech/Roche, Inventiva, Lilly, Pfizer, J. Pope Grant/research support from: Actelion, Bayer AG, Bristol-Myers Squibb, Merck, Pfizer Inc, Roche, Consultant for: Actelion, Bayer AG, Bristol-Myers Squibb, Merck, Pfizer Inc, Roche, C. Denton Consultant for: Actelion Pharmaceuticals US, Bayer AG, GlaxoSmithKline, CSL Behring, Merck-Serono, Roche Pharmaceuticals, Genentech and Biogen IDEC Inc., Inventiva, Sanofi-Aventis Pharmaceutical, Boehringer Ingelheim, Speakers bureau: Actelion Pharmaceuticals US, Bayer AG, GlaxoSmithKline, CSL Behring, Merck-Serono, Roche Pharmaceuticals, Genentech and Biogen IDEC Inc., Inventiva, Sanofi-Aventis Pharmaceutical, Boehringer Ingelheim, D. Khanna Shareholder of: Eicos, Grant/research support from: Bayer, Bristol-Myers Squibb, Boehringer Ingelheim, Genentech/Roche, NIH, Pfizer, SanofiAventis Pharmaceuticals, Consultant for: Actelion Pharmaceuticals US, Bayer, Bristol-Myers Squibb, Boehringer Ingelheim, Chemomab, Corbus, Covis, Cytori, Eicos, EMD Serono, Genentech/Roche, Pfizer, Gilead, GlaxoSmithKline, SanofiAventis Pharmaceuticals, and UCB Pharma, O. Distler Grant/research support from: Actelion, Bayer, Biogen Idec, Boehringer Ingelheim, ChemomAb, EspeRare Foundation, Genentech/Roche, GlaxoSmithKline, Inventiva, Lilly, Medac, Medlmmune, Mitsubishi Tanabe Pharma, Pharmacyclics, Novartis, Pfizer, Sanofi, Sinoxa, and UCB in the area of potential treatments of scleroderma and its complications. Patent mir-29 for the treatment of systemic sclerosis licensed, Consultant for: Actelion, Bayer, Biogen Idec, Boehringer Ingelheim, ChemomAb, EspeRare Foundation, Genentech/Roche, GlaxoSmithKline, Inventiva, Lilly, Medac, Medlmmune, Mitsubishi Tanabe Pharma, Pharmacyclics, Novartis, Pfizer, Sanofi, Sinoxa, and UCB in the area of potential treatments of scleroderma and its complications.

DOI: 10.1136/annrheumdis-2018-eular.5248

\section{SAT0514 MRI - GUIDED THERAPY FOR SYSTEMIC SCLEROSIS ASSOCIATED MYOSITIS}

Y. Braun-Moscovici ${ }^{1}$, D. Militianu ${ }^{2}$, N. Puchkov ${ }^{2}$, D. Markovits ${ }^{1}$, M. Braun ${ }^{3}$, M. A. Nahir ${ }^{1}$, A. Balbir-Gurman ${ }^{1} .{ }^{1}$ Rheumatology department, Rambam Health Care Campus, Rappaport Faculty of Medicine, Technion; ${ }^{2}$ Department of Medical Imaging, Rambam Health Care Campus, Rappaport Faculty of Medicine, Technion, Haifa; ${ }^{3}$ Liver Institute, Beilinson Hospital, Sackler School of Medicine, Tel Aviv University, Petach Tikva, Israe

Background: Muscle involvement in systemic sclerosis (SSc) has a significant impact on morbidity, functional capacity, and mortality. The muscle histopathology is heterogeneous including inflammatory and fibrotic changes. Currently there are no satisfactory means to diagnose inflammatory myopathy in SSc pts with normal creatine kinase (CK) and to assess the response to therapy.

Objectives: Our aim was to evaluate whether muscle magnetic resonance imaging (MRI) might be a tool to diagnose inflammatory myopathy in SSc patients (pts) and to assess the effect of muscle oriented-immunomodulatory therapy.

Methods: We retrospectively analysed the clinical data of 290 consecutive SSc pts seen at our centre between the years 2012-2017. Our cohort is part of the EUSTAR registry (centre 042). Pts with muscle weakness as defined by the Medsger muscle severity score of $>1$ and at least one MRI study were included. Clinical data analyzis included SSc subtype, disease duration, modified Rodnan skin score (mRSS), Medsger muscle severity score, CK, autoantibody profile, $\mathrm{MRI}$ and immunomodulatory treatment.

Results: 26 pts with muscle weakness answered the criteria of Medsger muscle severity score of $\geq 1 \mathrm{MRI}$ data were available, in 17 of the pts. Muscle oedema and fasciitis were seen in MRI in 13 pts (10 diffuse subset, median: age 40, disease duration 1.25 years, mRSS 13.5). MRI was normal in 4 pts (2diffuse SSc, median: age 50 years, disease duration 6 years, mRSS 4). CK was normal in 10 pts with pathologic MRI. Anti-topoisomerase was positive in 6 pts, RNA polymerase 3 - in 3 pts, anti-centromere - in 2 pts and 6 pts were only ANA positive. Muscle biopsy results were available in 4 pts: Biopsy was compatible with myositis in 3 pts with pathologic MRI and revealed fibrosis in 1 pt with normal MRI. 14 pts received immunomodulatory treatment: rituximab (3 pts), rituximab and intravenous immunoglobulins (IVIG) (3 pts), IVIG and methotrexate/azathioprine/mycophenolate mofetil. ${ }^{8} \mathrm{~A}$ second MRI was performed in 6 pts with first pathologic MRI, after 12 months of treatment. Significant regression of muscle oedema and perifasciitis was observed in 5 pts and correlated with clinical amelioration, with improvement of muscle strength. No clinical and imaging improvement occurred in one patient, despite the treatment. No change in muscle strength was seen in the patient with normal MRI and evidence of fibrosis on muscle biopsy, although the skin score improved.
Conclusions: MRI might serve as a non-invasive tool for diagnosis of inflammatory myopathy in SSc pts with early disease, Medsger muscle severity score of $\geq 1$ and normal CK and for assessment of treatment efficacy.

Disclosure of Interest: None declared

DOI: 10.1136/annrheumdis-2018-eular.6511

\section{SAT0515 CLINICAL CHARACTERISTICS OF PATIENTS WITH CANCER-ASSOCIATED MYOSITIS COMPLICATED BY INTERSTITIAL LUNG DISEASE}

Y. Kaneko $^{1}$, T. Nunokawa ${ }^{2}$, Y. Taniguchi ${ }^{3}$, Y. Yamaguchi ${ }^{4}$, T. Gono ${ }^{5}$, K. Masui ${ }^{6}$, A. Kawakami ${ }^{7}$, Y. Kawaguchi ${ }^{8}$, S. Sato ${ }^{9}$, M. Kuwana ${ }^{5}$ on behalf of JAMI investigators. ${ }^{1}$ Division of Rheumatology, Department of Internal Medicine, Keio University School of Medicine; ${ }^{2}$ Department of Rheumatic Diseases, Tokyo Metropolitan Tama Medical Center, Tokyo; ${ }^{3}$ Department of Endocrinology, Metabolism, Nephrology and Rheumatology, Kochi Medical School Hospital, Kochi; ${ }^{4}$ Department of Environmental Immuno-Dermatology, Yokohama City University Graduate School of Medicine, Kanagawa; ${ }^{5}$ Department of Allergy and Rheumatology, Nippon Medical School Graduate School of Medicine, Tokyo; ${ }^{6}$ Department of Anesthesiology, National Defense Medical College School of Medicine, Saitama; ${ }^{7}$ Department of Immunology and Rheumatology, Nagasaki University Graduate School of Biomedical Sciences, Nagasaki; ${ }^{8}$ Institute of Rheumatology, Tokyo Women's Medical University, Tokyo; ${ }^{9}$ Division of Rheumatology, Department of Internal Medicine, Tokai University School of Medicine, Kanagawa, Japan

Background: Cancer-associated myositis (CAM) is believed to be rarely complicated by interstitial lung disease (ILD), and, thus, detailed clinical characteristics of CAM in patients with polymyositis (PM)/dermatomyositis (DM)-associated ILD are not well known

Objectives: To clarify the incidence, risk factors, and impact on survival of malignancy in patients with $\mathrm{PM} / \mathrm{DM}$-associated ILD, using a large cohort data.

Methods: We used 497 patients with PM/DM-associated ILD enrolled in a multicentre retrospective cohort of incident cases from 44 institutions across Japan (JAMI). CAM was defined as malignancy diagnosed within 3 years before or after PM/DM diagnosis. Demographic data and clinical characteristics were recorded at the time of diagnosis, and follow-up survival and malignancy data were collected prospectively.

Results: Thirty-two patients with CAM (6.4\%) were identified. Patients in the CAM group were older (64.3 vs 55.1 years, $p<0.001$ ), had shorter disease duration at onset (4.1 vs 7.0 months, $p=0.01$ ), and presented with arthritis less frequently $(24.1$ vs $48.5 \%, p=0.01$ ), in comparison with those with non-CAM group. All patients with CAM were older than 40 years, and the proportion of CAM increased along with the age. Patients who were $\geq 59$ years at diagnosis and lacked arthritis were at 12 times higher risk for concomitant malignancy than those without such features (figure 1). Frequencies of autoantibodies, including antiMDA5, anti-ARS, and anti-TIF1gamma, were not different between the groups. In 19 patients $(59 \%)$, malignancy was diagnosed within 3 months before or after $\mathrm{PM} /$ DM diagnosis. Eleven CAM patients were died, and cause of deaths included ILD in 6 and malignancy in 5. Survival analysis by Kaplan-Miere method demonstrated that CAM patients had a poorer survival than did non-CAM patients $(p=0.016)$

Conclusions: In patients with PM/DM-associated ILD, older age at diagnosis and lack of arthritis are predictors for concomitant malignancy, which leads to a reduced survival.

Disclosure of Interest: Y. Kaneko Speakers bureau: Astellas, T. Nunokawa: None declared, Y. Taniguchi: None declared, Y. Yamaguchi: None declared, T. Gono: None declared, K. Masui: None declared, A. Kawakami: None declared, Y. Kawaguchi: None declared, S. Sato Grant/research support from: a patent on anti-MDA5 antibody-measuring kit, M. Kuwana Grant/research support from: Astellas, Speakers bureau: Astellas, Japan Blood Products Organisation, Medical and Biological Laboratories

DOI: 10.1136/annrheumdis-2018-eular.3601

\section{SATURDAY, 16 JUNE 2018}

\section{Vasculitis}

\section{SAT0516 TWO DISTINCT SUBSETS OF LOW DENSITY GRANULOCYTES IN ANCA ASSOCIATED VASCULITIS}

A. Endo, Y. Komagata, K. Yamagishi, N. Ikegaya, K. Fukuoka, M. Karube, Y. Arimura, S. Kaname. Division of Nephrology and Rheumatology, First Department of Internal Medicine, Kyorin University School of Medicine, Tokyo, Japan

Background: Low density granulocyte (LDG), a proinflammatory population of neutrophils, was first described in systemic lupus erythematosus (SLE) and has 